\title{
Innovative Technologies for the Production of Semi-Finished Meat Products as a Factor in the Development of the Consumer Market
}

\author{
Olga Chugunova, Arkadiy Ponomarev", Larisa Kokoreva, and Olga Feofilaktova \\ Ural State University of Economics, 620144 Ekaterinburg, Russia
}

\begin{abstract}
The article deals with topical issues of high-tech production development of minced meat semi-finished products with added benefits as an imperative of new industrialization. The use and processing of agricultural grain raw materials in the Sverdlovsk region will allow local enterprises of the agro-industrial complex to develop steadily and strengthen ties with potential consumers of processed grain raw materials. Creating innovative food products for mass consumption is one of the main tasks of the state policy in the field of healthy nutrition of the population. Research on the development of minced meat semi-finished products with the addition of food grain matrix is presented. An increase in the nutritional, biological and physiological value for the human body, the prospects of using grain matrix in the technology of production of minced meat products from poultry (turkey) have been established. The development of innovative food products is one of the priority areas for the development of the consumer market.
\end{abstract}

\section{Introduction}

Modern industrialization is aimed at ensuring significant savings in the use of natural resources, creating waste-free production and innovative products that minimize the negative impact on the environment.

Industrialization in the food industry is a new, highly efficient technology that can significantly improve the quality and safety of products, as well as provide an increase in its efficiency, understood in the broadest sense, including the use of modern equipment and prescription components.

Economic growth and overcoming structural crises require the development of promising technological approaches aimed at achieving sustainable development of the real sector of the economy and, above all, the consumer market. An important state task is the sustainable development of agricultural enterprises and producers of the agro-industrial complex of the Sverdlovsk region. In the framework of the Russian Federation Government Order of October 25, 2010 № 1873-p On approval of "Fundamentals of State Policy of the Russian Federation in the Field of Healthy Nutrition of the Population for the Period till $2020 "$ it is supposed to use mainly the resources of raw materials and food needs of the

* Corresponding author: arkadiy.ponomarev.69@mail.ru 
domestic industry. It is planned to prioritize the development of innovative research in the field of modern technologies for obtaining new food sources and medical and biological assessment of their quality and safety to create dietary products, functional products for the nutrition of sick and healthy children, and mass consumption, which are enriched with vitamins and minerals [1].

The health of society and each individual is largely determined by the diet. Rational / optimal nutrition of the population ensures active working capacity, increases human life expectancy and contributes to the preservation of the gene pool of the entire nation.

Currently, the problem of nutrition correction is relevant for all countries of the world, including Russia. And issues of healthy nutrition are elevated to the rank of state policy [14].

Inadequate consumption of animal fats, reduced consumption of dietary fiber, and insufficient consumption of vitamins and minerals [5] have been identified by various sociological and medical studies. Therefore, the creation of products that have a functional direction, including in semi-finished products from poultry meat, is relevant. As a source of functional food ingredients (FFI), cereals such as barley and oats can be used, which contain dietary fiber, minerals (especially potassium, magnesium, iron), and vitamins [6-8]. Studies have shown that as FFI, it is possible to use the medium-early variety of spring barley "Abalak" and oats of the variety "Memory of Balavin", as the most productive, grown in the Sverdlovsk region and processed into flour.

In the works by I. K. Nesterenko, L.V. Anisimova [6], E. S. Goltsova, E.N. Artemova [7], R. Prasad [9], K. Nelson [10] and others [11,17,19], the possibility of using oat and barley flour as an additive to increase the nutritional value of food products was studied. The influence of grain ingredients on the quality, nutritional value, safety and economic efficiency of chopped semi-finished products are considered in the works by Gurinovich G. A. [11], Reshetnik E.I. [12], Zubareva E. N. [13], Zinina O. V. [14] and others. However, a number of issues related to the use of processed products of barley and oats as a functional ingredient remain unsolved: the technological features of obtaining grain matrix have not been developed, its functional potential has not been studied, and there are no fundamental technological solutions for the use of grain matrix in the technology of minced meat products.

Oat flour is a source of protein, fatty acids, vitamins and mineral elements. Oat flour regulates fat metabolism, normalizes the work of the gastrointestinal tract $[6,9,11]$.

Barley flour contains a large amount of fiber, so it has a positive effect on digestion. In addition, it contains B vitamins (B1, B2) and vitamin PP, potassium, calcium, magnesium, and iron $[6-8,18]$.

Products made from cutlet mass are widely distributed in the diet of the population of Russia, both healthy and sick groups of the population and are included in the daily diet.

In connection with the above, the study and conduct of comprehensive research on the development of recipes for chopped poultry products using grain plant raw materials of the Ural region (grain matrix), namely barley and oat flour, is relevant, as it will contribute to expanding the range of chopped poultry products that can be recommended for all population groups.

The aim of the research is to develop minced meat products from poultry (turkey) with the addition of a multifunctional ingredient - a grain matrix with predictable consumer characteristics, which contributes to the prevention of macro - and micronutrient deficiencies. 


\section{Materials and Methods}

For use, two types of flour (barley and oat) are taken. Raw materials for matrix production are grown in the Sverdlovsk region. Barley and oat flour were compared with traditional (wheat of the highest grade, produced by JSC "Magnitogorsk Combine of Bakeries SITNO").

The objects of the study are:

- sample No. 1 - (control) - chicken cutlets (turkey) steamed;

- sample No. 2 - steamed poultry (turkey) cutlets with oat flour content of $100 \%$ of the norm of the prescription bookmark of wheat bread;

- sample No. 3 - steamed poultry (turkey) cutlets with a content of barley flour $100 \%$ of the norm of the prescription bookmark of wheat bread;

- sample No. 4 - steamed poultry (turkey) cutlets containing grain matrix (1) from oat and barley flour $100 \%$ of the norm of the prescription bookmark of wheat bread (30/70 $\%$, respectively);

- sample No. 5 - steamed poultry (turkey) cutlets containing grain matrix (2) from oat and barley flour $100 \%$ of the norm of the prescription bookmark of wheat bread (40/60 $\%$, respectively);

- sample No. 6 - steamed poultry (turkey) cutlets containing grain matrix (3) from oat and barley flour $100 \%$ of the norm of the prescription bookmark of wheat bread $(50 / 50$ $\%$, respectively);

- sample No. 7 - steamed poultry (turkey) cutlets containing grain matrix (4) from oat and barley flour $100 \%$ of the norm of the prescription bookmark of wheat bread $(60 / 40$ $\%$, respectively);

- sample No. 8 - steamed poultry (turkey) cutlets with a grain matrix content (5) of oat and barley flour $100 \%$ of the norm of the prescription bookmark of wheat bread (70/30 $\%$, respectively).

In the analysis of the theory, methods of systematization, modeling, comparison, classification, generalization, as well as expert assessments were used. During the experiment, organoleptic, physico-chemical and culculation methods of research were used. Studies of experimental works were carried out in 3-5-fold repetition and processed statistically using the MS Excel application software package.

The quality of raw materials and finished products was determined by the method described below:

- organoleptic quality indicators of finished products were determined according to GOST 31986-2012. The main organoleptic indicators for chopped cutlets are: appearance, color, smell, consistency and taste.

- the mass fraction of moisture or dry matter was determined using the accelerated weight method according to GOST 5900-2014. The essence of the method consists in drying the hitch at a set temperature to a constant dry mass and determining the mass loss in relation to the hitch. Drying of the products was carried out in the RF device in special packages to a constant mass.

- the mass fraction of fat was determined according to GOST 5900-2014, by extraction and weight method. The method is based on extraction of fat from a sample exagerada mixture (chloroform: alcohol - 2: 1) and subsequent evaporation in the drying cabinet to a constant mass of the remaining fat.

- the amino acid composition was determined using the method of ion exchange chromatography on "Aminoacid Analyzer T339M" in accordance with the instructions for using the equipment. The method is based on the distribution of ions of a mixture of 
one sign of charge between the solution and the ion exchanger (ionite). Ion exchangers absorb positively or negatively charged ions from the solution in exchange for an equivalent number of ions of the same charge sign of the ion exchanger.

- the food and energy value of the product was determined by the calculation method based on the norms of human need for basic nutrients and data on the chemical composition of food products [20].

\section{Results and Discussion}

Development of recipes and technology of grain matrix

Food grain matrix is a fine-grained homogeneous mixture obtained as a result of grinding the grains of various cereals.

Various cereals can be used to produce the grain matrix. In our case, we used grain grown in the Sverdlovsk region.

The technology of production of food grain matrix provides the following technological operations:

- Preparation of raw materials. In the production of oat flour, after primary threshing, the grains are washed and steamed to produce flakes, then they are thoroughly dried and ground into flour. Artificial moistening of barley and oats to optimal humidity (up to $21-22 \%$ ) contributes to the production of fine and soft flour, while the processing of dry barley and oats makes the flour crumbly and coarse.

- Preparation of grain matrix. Dosing and mixing is carried out in a batch production mixer with special dispensers. The process takes 5-7 minutes.

- Packaging and storage. With the help of a packaging device, the mixtures are dosed into a polyethylene teraphthalate package (weight $500 \mathrm{~g}$ ). Storage $\mathrm{t}=5-15{ }^{\circ} \mathrm{C}$, humidity-60-70\%.

Since we offer the replacement of wheat bread used in the recipes of minced meat products, the next step is a comparative assessment of the chemical composition of Abalak barley flour, Balavin Memory oat flour grown in the Sverdlovsk region in comparison with wheat flour of the highest grade produced by JSC "Magnitogorsk Combine of Bakerries = SINTO" and wheat bread of the highest grade (Table 1).

As follows from the presented data, barley and oat flour produced at the food enterprise from raw materials grown in the Urals is richer in fats and proteins compared to traditional wheat flour and wheat bread. This is especially true for oat flour. The fat content in it exceeds traditional wheat flour by 5.3, and protein - by 1.3 times. Oat flour is also superior to wheat in terms of dietary fiber content. The carbohydrate content of barley and oatmeal is lower than that of wheat flour due to the lower starch content. The use of barley and oat flour in the production of chopped poultry products (when replacing wheat bread) will enrich them with proteins, fats, dietary fibers and carbohydrates.

Table 1. Comparative chemical composition of barley, oat flour, wheat flour and wheat bread, g per $100 \mathrm{~g}$ of the product.

\begin{tabular}{|l|c|c|c|c|}
\hline Food Substances & Wheat Flour & Wheat Bread & Barley Flour & Oat Flour \\
\hline Protein, g & $10,52 \pm 0,01$ & $6,59 \pm 0,05$ & $11,21 \pm 0,05$ & $13,63 \pm 0,02$ \\
\hline Fat, g & $1,22 \pm 0,01$ & $0,64 \pm 0,01$ & $1,73 \pm 0,01$ & $6,46 \pm 0,01$ \\
\hline Carbohydrates,g & $69,90 \pm 0,4$ & $49,20 \pm 0,5$ & $56,10 \pm 0,5$ & $64,90 \pm 0,8$ \\
\hline Dietary fiber, g & $3,50 \pm 0,2$ & $2,60 \pm 0,1$ & $7,40 \pm 0,1$ & $6,50 \pm 0,1$ \\
\hline Beta-glucan, g & - & - & $6,8 \pm 0,2$ & $5,4 \pm 0,2$ \\
\hline Water, g & $13,75 \pm 0,03$ & $37,42 \pm 0,02$ & $14,11 \pm 0,01$ & $8,76 \pm 0,02$ \\
\hline
\end{tabular}


The highest content of proteins in general and amino acids in particular is characterized by oat flour (Fig. 1). The second place in biological value is occupied by barley flour. Wheat flour and wheat bread are significantly inferior in biological value to oat and barley flour. Therefore, the use of these types of flour in the production of semi-finished products, dishes (products) will increase the nutritional and biological value of the product.

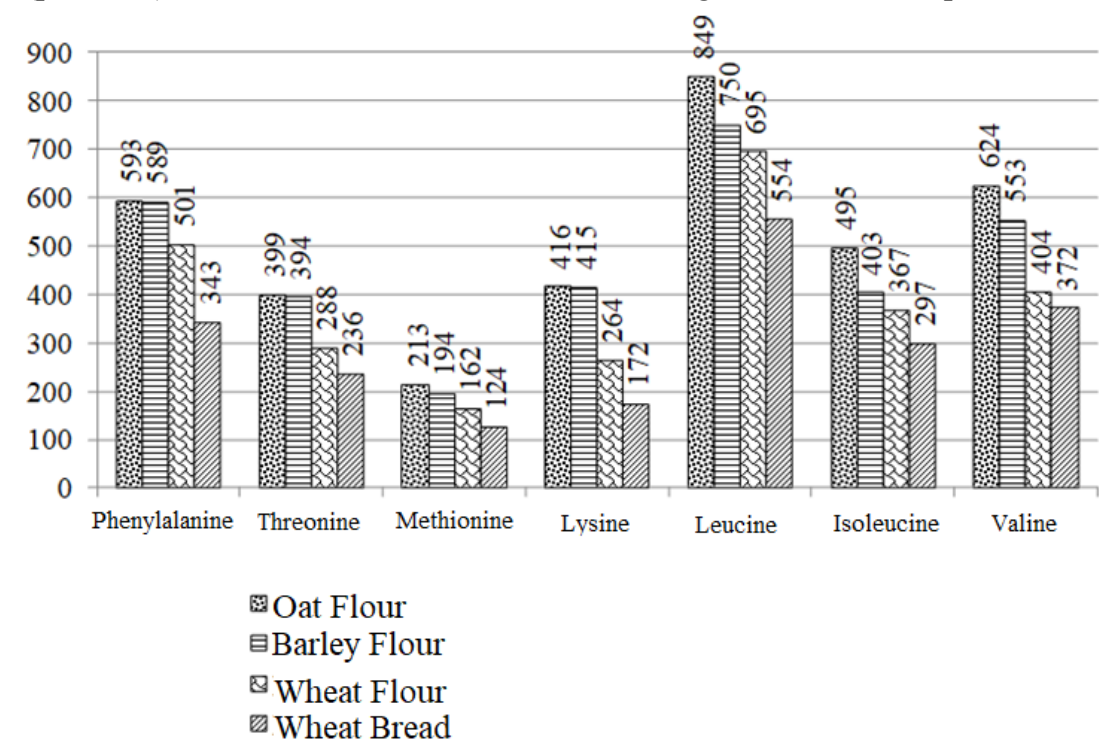

Fig. 1. The content of essential amino acids in the types of flour used and wheat bread from premium flour, $\mathrm{mg} / 100 \mathrm{~g}(\mathrm{n}=3)$

Development of recipes for products made from chopped mass using food grain matrix. The recipe for steamed turkey meatballs according to the Collection of recipes for dietary dishes (recipe No. 651) [15] and experimental samples of minced meat semi-finished products from poultry meat is presented in Table 2 .

Table 2. Recipes for meatballs chopped from poultry meat.

\begin{tabular}{|c|c|c|c|c|c|c|c|c|}
\hline \multirow{3}{*}{$\begin{array}{l}\text { Chemical } \\
\text { composition }\end{array}$} & \multicolumn{2}{|c|}{ Sample №1 } & \multicolumn{2}{|c|}{ Sample №2 } & \multicolumn{2}{|c|}{ Sample №3 } & \multicolumn{2}{|c|}{ Sample №4 } \\
\hline & \multicolumn{8}{|c|}{ weight, g } \\
\hline & gross & net & gross & net & gross & net & gross & net \\
\hline Poultry (turkey fillet) & 126,0 & 78,0 & 126,0 & 78,0 & 126,0 & 78,0 & 126,0 & 78,0 \\
\hline Wheat bread & 15,0 & 15,0 & - & - & - & - & - & - \\
\hline Food salt & 0,5 & 0,5 & 0,5 & 0,5 & 0,5 & 0,5 & 0,5 & 0,5 \\
\hline Drinking water & 21,0 & 21,0 & 21,0 & 21,0 & 21,0 & 21,0 & 21,0 & 21,0 \\
\hline Oat flour & - & - & 15,0 & 15,0 & - & - & 4,5 & 4,5 \\
\hline Barley flour & - & - & - & - & 15,0 & 15,0 & 10,5 & 10,5 \\
\hline Product output & & 100,0 & & 100,0 & & 100,0 & & 100,0 \\
\hline & San & №5 & Sam & №6 & Sam & №7 & San & №8 \\
\hline Poultry (turkey fillet) & 126,0 & 78,0 & 126,0 & 78,0 & 126,0 & 78,0 & 126,0 & 78,0 \\
\hline Drinking water & 21,0 & 21,0 & 21,0 & 21,0 & 21,0 & 21,0 & 21,0 & 21,0 \\
\hline Food salt & 0,5 & 0,5 & 0,5 & 0,5 & 0,5 & 0,5 & 0,5 & 0,5 \\
\hline Oat Flour & 6,0 & 6,0 & 7,5 & 7,5 & 9,0 & 9,0 & 10,5 & 10,5 \\
\hline Barley Flour & 9,0 & 9,0 & 7,5 & 7,5 & 6,0 & 6,0 & 4,5 & 4,5 \\
\hline Output & & 100,0 & & 100,0 & & 100,0 & & 100 \\
\hline
\end{tabular}


Technology of cooking steamed turkey meatballs.

Poultry fillet (turkey) is washed under running water and dried, then 1-2 times crushed in a meat grinder, add bread soaked in water (or grain matrix diluted in water (1:2)), again crushed in a meat grinder, add salt, knead well. Meatballs are formed and steamed in a combi oven at a temperature of $180^{\circ} \mathrm{c}$ for $15-20$ minutes.

Organoleptic and physico-chemical indicators of the quality of chopped products.

Organoleptic analysis showed that the best option for the production of chopped cutlets from turkey meat is sample No. 5, which uses a food grain matrix with a ratio of oat and barley flour-40/60\%. This sample kept its shape well, the product was without cracks, rounded-flattened shape with a pointed end. The consistency is uniform, soft. The color of the product is light cream, on the cut - light cream. The taste of the product is boiled turkey, moderately salty. The smell is peculiar to turkey. Without extraneous taste and smell.

The appearance and consistency of products using oat flour above 50\% (samples 3, 4, 6, 7) had insufficient moisture binding ability, the products had a very loose consistency compared to the control sample.

The consistency of the product with a complete replacement of wheat bread with oat flour, as well as with a $70 \%$ replacement of the mass of bread, was heterogeneous, viscous. The product had an unpleasant taste when chewed.

Physical and chemical parameters of objects 1 and 5 are presented in Table 3.

It is established that the introduction of food grain matrix in chopped poultry products increases the nutritional value of the product in all food substances. As a result, the energy value increases by $33 \mathrm{kcal}$.

Table 3. Comparative physical and chemical indicators samples No. 1 and 5, g per $100 \mathrm{~g}$ of product / kcal.

\begin{tabular}{|l|c|c|c|}
\hline $\begin{array}{c}\text { Food substances, } \\
\text { Energy value }\end{array}$ & Sample 1 & Sample 5 & deviations, \pm \\
\hline Protein, $\Gamma$ & $14,93 \pm 0,02$ & $15,86 \pm 0,01$ & $+0,93$ \\
\hline Fat, $\Gamma$ & $9,65 \pm 0,01$ & $12,08 \pm 0,02$ & $+2,43$ \\
\hline Carbohydrates, $\Gamma$ & 7,01 & 8,75 & $+1,74$ \\
\hline Dietary fiber, $\Gamma$ & 0,37 & 0,48 & $+0,11$ \\
\hline Dry substances, $\Gamma$ & $33,46 \pm 0,03$ & $37,51 \pm 0,02$ & $+4,05$ \\
\hline Energy value, kcal & 175 & 208 & +33 \\
\hline
\end{tabular}

Table 4 presents a comparative analysis of the content of vitamins and minerals in the control sample and sample No. 5 using a food grain matrix (4).

Table 4. Comparative content of vitamins and minerals in cutlets chopped from poultry (turkey), $\mathrm{mg}$ per $100 \mathrm{~g}$ of the product.

\begin{tabular}{|l|c|c|c|c|c|c|c|c|c|c|}
\hline \multirow{2}{*}{$\begin{array}{c}\text { The objects } \\
\text { of study }\end{array}$} & \multicolumn{6}{|c|}{ Vitamins, mg / 100 g } & \multicolumn{6}{|c|}{ Minerals, mg/100 g } \\
\cline { 2 - 10 } & $\mathbf{B}_{\mathbf{1}}$ & $\mathbf{B}_{\mathbf{2}}$ & $\mathbf{B}_{\mathbf{5}}$ & $\mathbf{B}_{\mathbf{6}}$ & $\mathbf{C a}$ & $\begin{array}{c}\mathbf{M} \\
\mathbf{g}\end{array}$ & $\mathbf{K}$ & $\mathbf{P h}$ & $\mathbf{F e}$ & $\mathbf{S e}$ \\
\hline Object 1 & 0,12 & 0,02 & 0,18 & 0,10 & 17,26 & 12,78 & 84,79 & 62,62 & 0,95 & 0,004 \\
\hline Object 7 & 0,17 & 0,04 & 0,19 & 0,12 & 23,42 & 26,16 & 112,43 & 105,07 & 1,31 & 0,006 \\
\hline Deviations, \pm & $+0,05$ & $+0,02$ & $+0,01$ & $+0,02$ & $+6,16$ & 13,38 & $+27,64+42,45$ & $+0,36$ & $+0,002$ \\
\hline
\end{tabular}

The inclusion of food grain matrix in the recipe of minced meat products from poultry has a positive effect on their vitamin and mineral composition, increases the physiological value for the human body. There is an increase in all the vitamins and minerals presented. In particular, the content of phosphorus (by $42.45 \mathrm{mg}$ ) and potassium (by $27.64 \mathrm{mg}$ per 100 $\mathrm{g}$ of the finished product) increased. 


\section{Conclusions}

Processing and use of grain raw materials grown in the Sverdlovsk region, will allow sustainable development to local manufacturers, and the introduction of food grain matrices in the compounding and technology of semi-finished products, dishes (products) catering facilities will enhance the offer in the market of assortment, creation of new functional foods, which is one of the tasks of industrialization of public catering, and also defined by the government of the Russian Federation from October 25, 2010 N 1873-R "On approving the Fundamentals of State Policy of the Russian Federation in the Field of Healthy Nutrition of the Population for the Period till 2020".

Food grain matrices can be drawn up and made from any grain, agricultural raw materials, but when designing it is necessary to consider functional and technological properties of raw materials, organoleptic compatibility, and operational reserves.

It should be noted the high nutritional, biological and physiological value of the developed food grain matrix, as the content of amino acids and protein in general, the content of fatty acids, dietary fiber, vitamins and minerals increases.

This work showed the prospects of using grain matrix in the production of chopped semi-finished products from poultry meat (turkey). The finished products had good organoleptic quality indicators, which were not inferior to the control object of the study. And the raw materials used and the technology of making chopped cutlets allows us to recommend the product for production in the canteens of preventive and medical institutions, since it corresponds to the main version of the standard diet, increases the biological and physiological value of the finished product.

Thus, the consumer market in the context of the new economy plays an important role in the economy of the region. Thus, the development of the territory's consumer market depends on innovative developments, including in the food industry and public catering. Therefore, one of the directions of development of consumer markets is to increase the competitiveness of manufactured consumer goods.

\section{References}

1. N.V. Leiberova, O. V. Chugunova, N.V. Zavorokhina, Economy of the region, 4, 142 (2011)

2. R.V. Kunakova, R.A. Zaynullin, E.K. Khusnutdinova, B.I. Yalaev, Bulletin of the Academy of Sciences of the Republic of Bashkortostan, 21, 3(83), 5 (2016)

3. N.F. Gerasimenko, V.M. Poznyakovskiy, N.G. Chelnokova, Technologies of food and processing industry of the agro-industrial complex - healthy food products, 4(12), 52 (2016)

4. R.I. Fattakhova, New Science: Strategies and Development Vectors, 118-3, 51 (2016)

5. S.Yu. Baglushkina, N.V. Yefimova, I.Yu. Tarmayeva, Public health and habitat, 6 (267), 23 (2015)

6. I.K. Nesterenko, L.V. Anisimova, Biotechnology and Society in the XXI Century, International Scientific and Practical Conference, 220 (2015)

7. Biotechnology and Society in the XXI Century, International Scientific and Practical Conference, 438 (2018)

8. J. A. Delcour, R. C. Hoseney, Principles of cereal science and technology, 280 (2009)

9. R. Prasad, J. Alok, S. Latha, K. Arvind, V.S. Unnikrishnan, J. Food Sci. Technol. Vol. 52 no. 2, Pp. 662-675 (2015)

10. K. Nelson, L. Stojanovska, T. Vasiljevic, M. Mathai, Canadian Journal of Physiology and Pharmacology, 91(6), 429 (2015) 
11. V. Sternaa, S. Zuteb, L. Brunavaa, Agriculture and Agricultural Science Procedia, 8, 252 (2016)

12. E.I. Reshetnik, V.A. Maksimyuk, T.V. Sharipova, The potential of modern science, 2 (10), 62 (2015)

13. E.N. Zubareva, I. S. Patrakova, G. V. Gurinovich, N. N. Potipaeva, Meat industry, 12, $20(2011)$

14. O.V. Zinina, K.S. Gavrilova, M.A. Pozdnyakova, Bulletin of the South Ural State University, Series: Food and Biotechnology, 1, 31 (2019)

15. L.E. Golunova, Collection of recipes for dishes and culinary products for catering, 688 (2006)

16. A.N. Beloshapka, P.R. Buff, G.C. Fahey, K.S. Swanson, J. Foods, 5, 1 (2016)

17. S. Bellaio, S. Kappeler, E. Z. Rosenfeld, M. Jacobs, Cereal foods world, 58(2), 231 (2014)

18. A. Fardet, Nutrition research reviews, 23, 65 (2010)

19. B. Tian, B. Xie, J. Shi, Food chemistry, 119(3), 1195 (2010)

20. V.A. Tutelyan, D.B. Nikityuk, S.A. Khotimchenko, Russian Journal of Rehabilitation Medicine, 2, 74 (2017) 